\title{
Editorial
}

\section{The human side of GMO biosafety research}

\author{
Mark TEPFER \\ Lab. of Plant Cell and Molecular Biology, INRA-Versailles, 78026 Versailles Cedex, France \\ E-mail: Mark.Tepfer@versailles.inra.fr
}

As you will have noticed from this issue of EBR, our cover photo contest was a success. To our surprise, we had several excellent entries that are quite different from the usual journal cover photo, since rather than presenting results, they show people working in GMO biosafety. Those of us involved in selecting the cover thought that some of these human interest photos would be worth publishing.

One of the issues in the area of commercial use of transgenic plants expressing a $B t$ endotoxin gene is the potential for unintended effects on non-target insects. Figure 1, which was submitted by Detlef Bartsch (Berlin, Germany), shows three members of his team (Andreas Toschki, Markus Tepner, and Rene Mause) setting up pitfall traps and cages for catching soil-inhabiting arthropods, in a field study of the potential impact of $B t$ maize on non-target insects. The experiment consists of several 0.5 ha plots (six replications each) with three treatments: $B t$-maize (expressing a $C r y l A b$ gene), isogenic maize sprayed with chemical insecticides, and isogenic maize without insecticides as a control. The aim is to make a complete inventory of arthropods living in the different plots over a three year period. If differences in species abundance between the treatments are observed, more in-depth studies with single species or species combinations may follow. One final goal is to identify keystone species for long-term monitoring of environmental effects. Meanwhile, Detlef Bartsch is now working in governmental regulation, and has handed over the project to Martina Ross-Nickoll and Achim Gathmann at the University of Aachen.

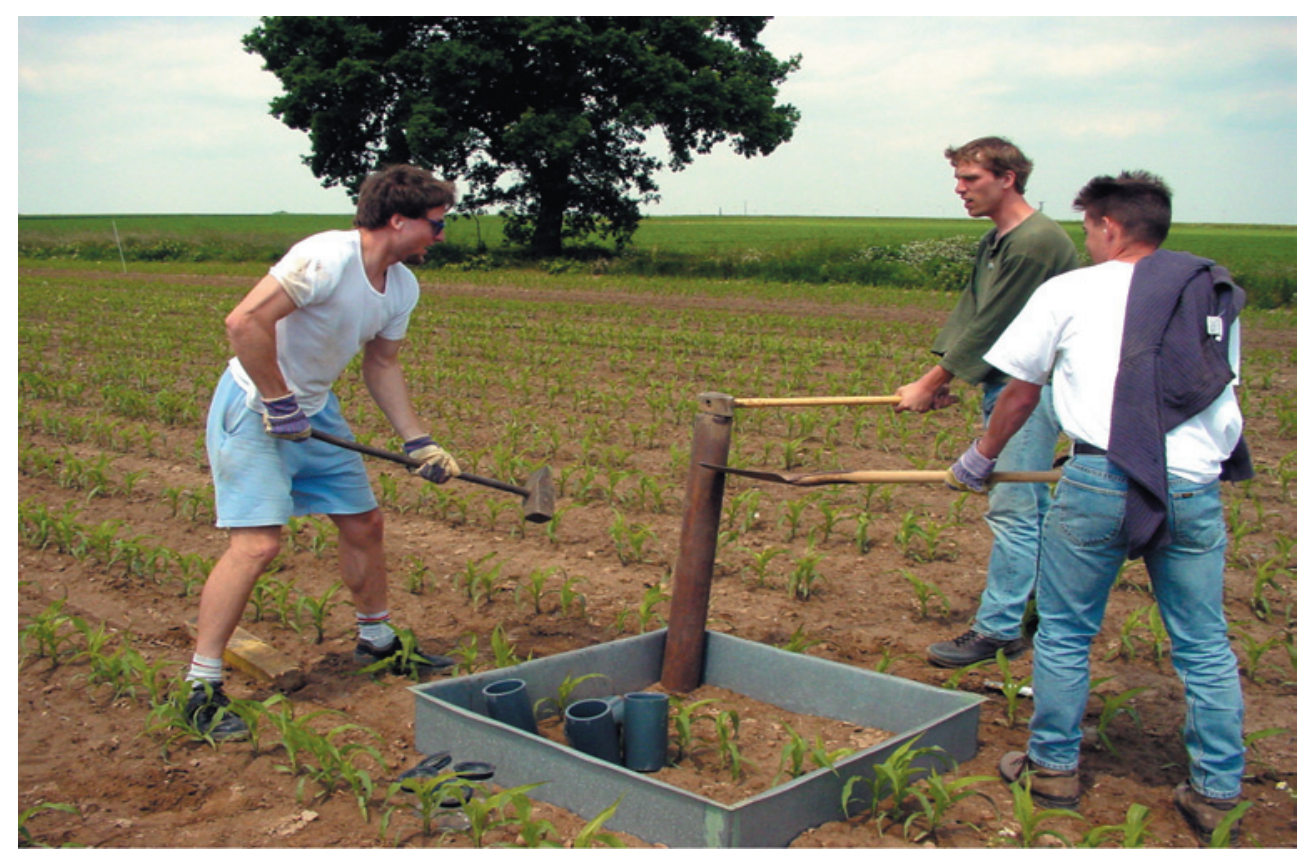

Figure 1. Setting up pitfall traps in a field study in Germany of the effects of Bt maize on arthropod populations. 


\section{Tepfer}

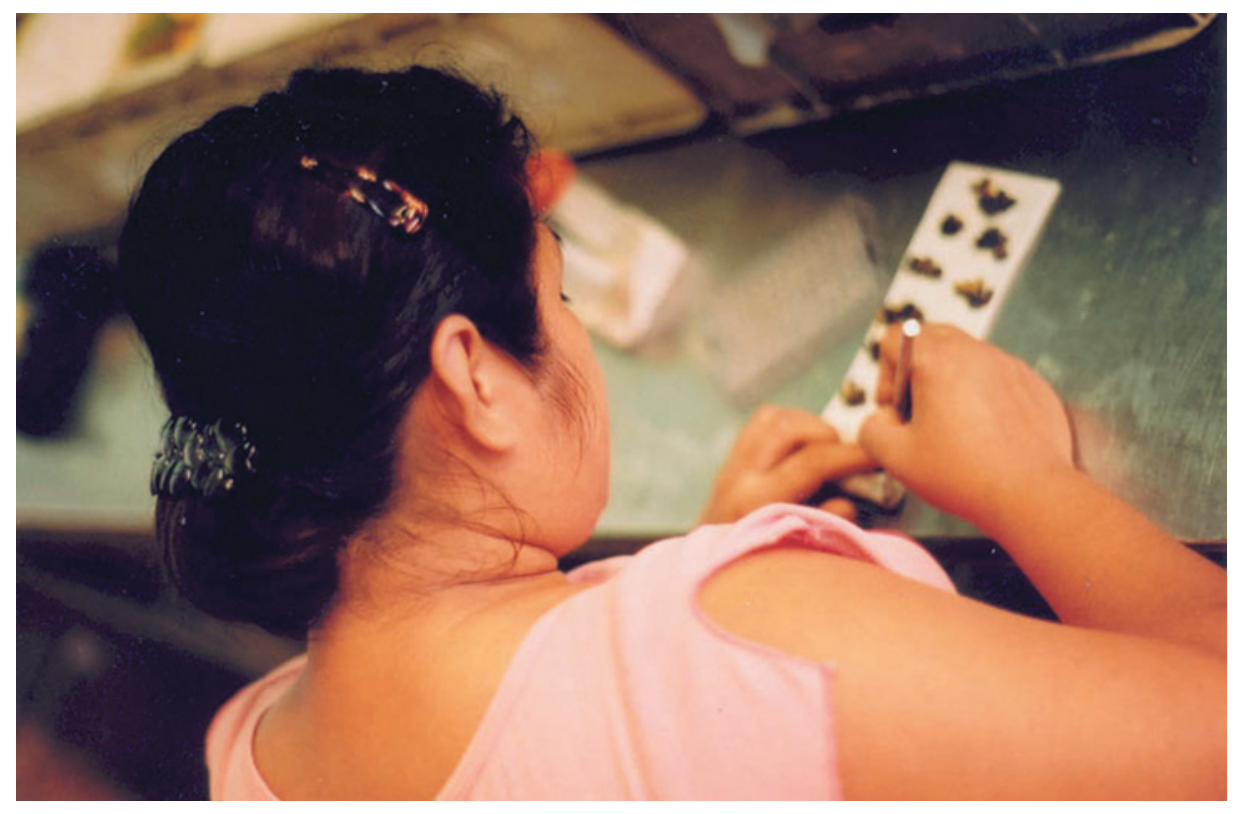

Figure 2. Final verification of the absence of GUS activity in non-GM papaya in a packing plant in Hawaii dedicated to non-GM papaya for export.

The transgenic papaya resistant to Papaya ringspot virus that was developed by Dennis Gonsalves's group is one of the rare cases of successful commercialization of virus-resistant transgenic plants. This has required the papaya industry in Hawaii to be in the forefront of dealing with real-life integration of transgenic plants in agriculture. Figure 2 is a photo taken by Ervin Balázs (Gödöllö, Hungary) in a papaya packing plant in Hawaii that is specialized in non-transgenic papaya for export to Japan. The person shown is doing an X-gluc test for GUS activity on seeds of non-transformed fruit, which is the last step in the protocol guaranteeing the absence of transgenic papaya in the fruit being prepared for export. The system put in place shows that co-existence and segregation of GM and non-GM products can be managed with rather simple means. However, the presence of a GUS gene in the transgenic papaya is a key point in making possible this low-cost and efficient screening process.

EBR is planning to continue changing its cover photo on a yearly basis. So as the year goes by, please continue to send us photos that you would like for us to consider for the cover of EBR in 2005. As Detlef Bartsch said in the message sent with his submissions, "It's very often the engagement of the scientists that counts...", and it is certainly true that all of us involved in producing EBR are counting on your participation in all aspects of the journal, in order to continue making the contents of EBR as much of a success as its cover. 